vol.4 No.1 - 2017

\title{
NURSING MANAGERS' COMPETENCY AND THEIR PROBLEM SOLVING STYLES \\ ${ }^{1}$ Heba Rabie Hagras, ${ }^{2}$ Wafaa Fathi Sleem, ${ }^{3}$ Sahar Hassan Helaly \\ 1 B.Sc of Nursing Science, 2, 3 Nursing Administration, Faculty of Nursing, Mansoura University heba58414@yahoo.com
}

\begin{abstract}
Nursing managers should enjoy appropriate competency level and knowledge that enhance their creative problem solving style. Aim of the study: The present study aimed to assess perceived nursing manager's competency, determine problem solving styles of nursing managers and detect the relation between nursing mangers' competency and their problem solving styles. Subjects and methods: a descriptive correlation design was utilized to attain the aim of the present study. The study sample included 97 nurse mangers working in Mansoura university hospital data was collected with using tool consisted of three parts: personal characteristics, Nursing Manger Competency Inventory (NMCI), and four sight problem solving style inventory. Conclusion: Majority of nursing mangers had moderate level of competency. Majority of nursing mangers had developer problem solving style and problem solving style level was moderate as perceived by the studied sample. There was significant relation between nursing manger competency level and problem solving style. Recommendation: Provide training programs to nursing mangers to enhance their competency level. Provide training programs about the importance of creativity for enhancing organization ability and efficiency, and how mangers can use their problem solving styles effectively. Draw up visions of nursing management in the future by health care organizations.
\end{abstract}

Key words: Nursing manger, Competency, Problem solving style

\section{Introduction:}

The dramatic reforms and changes in the health service in current years, rising from both strategy and review, have had, and will continue to have, a significant influence on the method in which the health service is managed ${ }^{\mathbf{1}}$. These changes brought about a requisite for mangers to acquire new roles and develop new skills. The new managerial responsibilities located on organized nursing services request for nurse mangers that are skilled, knowledgeable and competent in all aspects of management ${ }^{2}$.

Competence is defined in terms of functional adequacy and the capability to incorporate knowledge, skills, approaches and beliefs in definite contextual situations of practice" 3 . Other definitions include essential abilities and capabilities to accomplish the job well, and use descriptive language such as capabilities, traits, intelligence, and human capacities to define competence ${ }^{4}$.

Nurse Manager Competency is not only the performance or behaviors itself. But the repertoire of abilities, actions, procedure, and responses accessible that allows arranging of work requirements to be done successfully. This competency is not the same thing as performances, but it's what empowers the performances to happen and competency then is a concept that represents a constellation of the characteristics and abilities of the manger that leads to effective performance $\mathbf{5}$.

Nurse Managers are directly in charge for maintaining standards of care, managing fiscal resources, and developing self. Their responsibilities differ from organization to another, but the most effective nurse mangers identify the importance of point care leaders ${ }^{6}$. Key skills and competencies 
that assist managers to be effective in their role are critical thinking that requires an active stance manager rather than a passive one, communication skills, networking ,managing resources such as budgeting and staffing, enhance nurses performance through monitoring, team building and evaluating effectiveness and efficiency. Another competencies needed are delegating, collaboration, coordination and outcome oriented ${ }^{7}$.

Today, all responsible people in all affairs are recalled to high thinking skills and problem-solving whether in public field or in technology environment and whether in normal activities or in those activities which have problem, in most societies, it is supposed that we should more emphasize on increasing problem-solving skills ${ }^{8}$. Since nursing managers are responsible for prediction, prevention and solving problems, so the problem-solving which including improving the quality, creating an intimate environment and applying an effective method, in fact it is regarded as one of the major skills of management 9 .

Problem solving is defined as continuous thinking and selecting according to the desired goal .Fundamentally, the problemsolving is an attempt to find a solution for a problem ${ }^{10}$. It was said that a problem happens when there is a goal to be reached and it is not obvious how to reach it. Some problems are well defined, while others are ill defined $\mathbf{1 2}^{\mathbf{2}}$.

In management, problems arise when changed or new situations happen and they repeatedly requisite novel solutions. Commonly, it is a challenge to understand solutions of problems by thinking in a predictable manner. Logical thinking uses our existing knowledge and takes inference rules to produce new knowledge. Conversely, as logical thinking growths in chains of steps, every one dependent on the previous, this new knowledge is merely an extension of what we already know, rather than being actually new. It would appear; consequently, that logical thinking only has a restricted role to play in assisting managers for being creative. The requisite for creative problem solving has risen as an effect of the lacks of using imagination alongside with methods which use analogies, associations and other tools to support producing insights to problems $^{12}$.

Creative problem solving (CPS) is "defined as looking for original ways to achieve goals when the ways to do so are not readily obvious". A solver's abilities, styles, knowledge and other assets match to some degree the intellectual demands and complication of given problems. Problems may be solved by various ways, but the more efficient will consume less time, effort, and other resources for doing so ${ }^{13}$.

Erozlean (2014) indicated that problemsolving results are mainly determined by orientation of the problem and problemsolving style $^{14}$. Treffinger, et al (2008) defined problem-solving styles as constant individual alterations in the means people desire to plan and accomplish generating and concentrating actions, for increasing clarity, produce ideas, and arrange for action. This definition is attached with an individual or intrapersonal level of analysis as it incorporates a person's constant preference from a psychological point of view. Further, it comprises both divergent (generating) and convergent (focusing) classes of problem solving intended to gain clarity when face vague or ill-structured situational demands, creating unique ideas and alternatives, and building and developing options and plans for implementing original insights ${ }^{15}$.

There are four creative problem solving styles identified as clarifiers, ideations, developers and implementer. Clarifiers need a pure understanding of the problem and favor a systematic method for solving problems. Ideations enjoy toying with 
notions and potentials. They take an intuitive attitude to origination. Developers like analyzing possible solutions and planning the phases to implement a notion. Implementers like to get things done. They permanently just do it. Each manager can and does utilize each aspect of their personality, but they may have tendency to overuse the problem solving style which is most comfortable, rather than the style which may be more suitable to the problem at hand ${ }^{\mathbf{1 6}}$.

\section{Significance of the study:}

Strong managerial competencies have been recognized as key fundamentals to encourage health systems that are approachable to population needs. Given the requisite to implement health policies in reduced resources and challenging circumstances, health managers need to have managerial competencies. These competencies contain the behaviors, knowledge, skills, approaches and beliefs that inspire leadership and management activities ${ }^{17}$. It was said that knowledge can be utilized to produce and facilitate novel problem solving notions and that these notions can be used as the creation blocks from which to develop and offer excellence in service and other effective workplace practices ${ }^{\mathbf{1 8}}$.

\section{Aim of the study}

This study aims to assess perceived nursing mangers' competency and their problem solving styles at Main Mansoura University Hospital.

\section{Research questions}

\section{RQ1:}

What is the perceived nursing managers' competency?

\section{RQ2:}

What are the problem solving styles of nursing managers'?

\section{RQ3:}

Is there a relation between nursing mangers' competency and their problem solving styles?

\section{Subject and method}

Research design:

Descriptive correlation design was used in the present study.

\section{The study setting :}

The present study was conducted at Mansoura University Hospital (MUH). The hospital Provides care at delta region and bed capacity is (1800) beds.

\section{The study subject:}

The study sample included all nurse mangers available at the time of data collection in the previously mentioned settings. Their total numbers were 97 nurse managers classified as the following: (85) head nurses, (11) supervisors and (1) nurse director.

Tool of data collection-:

Data collection tool was including three parts; personal characteristics, Nurse Mangers' Competency Inventory (NMCI) and Four Sight Problem Solving Styles Inventory

1 st part:

Personal characteristics of nursing mangers such as age, level of education, position, marital status, and years of experience and span of control.

$2^{\text {nd }}$ Part: Nurse Mangers' Competency Inventory (NMCI):

This inventory was developed by Deonna (2006) which used to assess nursing mangers' competency. It included 93 item divided into eleven competency domains: promote staff retention, recruit staff, facilitate staff development, perform supervisory responsibilities, ensure patient safety \& quality care, conduct daily unit operations, manage fiscal planning facilitate interpersonal, group organizational communication, lead quality improvement initiatives, promote professional practice model, and develop self. The responses to each item on the (NMCI) according to the following 5point Likert response scale:- 
( 1 = none of the time, $2=$ occasionally, 3

= fairly many times, $4=$ Very Often, $5=$ Always) ${ }^{19}$.

The total scores of perceived competency questions ranged from 93-465. It was categorized into three levels based on cut of point $50 \%$ as the following:

-Low competency $<50 \%$ (scored from 93278)

-Moderate competency 50-75\% (scored from 279-372)

-High competency > 75\% (scored from 373-465)

\section{$3^{\text {rd }}$ part:}

Four Sight Problem Solving Styles

Inventory (version 6.1) developed by Puccio (2002) used to assess creative problem solving styles. It consists of 37 items. The first item not scored and the four styles are clarifier (9 items), implementer ( 9 items), ideator (9 items) and developer (9 items). The responses ranged from $1=$ not like me at all, $2=$ like me and $3=$ very like me ${ }^{20}$.

The total scores of problem solving styles questions ranged from 36-108. The scores of problem solving styles were categorized into three levels based on cut of point $50 \%$ as the following:

-Low problem solving styles scores $<50 \%$ (scored from 36-71)

-Moderate problem solving styles scores $50-75 \%$ (scored from 72-90)

-High problem solving styles scores $>75 \%$ (scored from 91-108)

\section{Validity:}

It was recognized for face as well as content validity via a panel of five expertise's from faculties of nursing.

Pilot study :

A pilot study was carried out on 9 nurse mangers as $10 \%$ of the study sample to test the clarity, feasibility of the questions and to determine the time needed to fill-in questions. Nurse mangers who shared in the pilot study were excluded in the main study sample. Based on the pilot study, necessary modification includes clarification, rewording. Reliability test of the study tools, nurse mangers' competency inventory and four sight problem solving styles inventory, were tested by Cronbach's Alpha reliability was computed and found (0.901), (0.887) respectively.

\section{Field work description:}

Collecting data from nurse mangers by explaining to each participant the aim of the study and take her acceptance.

Filling the questionnaire sheet acquired from 20-30 minutes; this time was dependent on the work conditions. Data collection for some participants was carried out through distribution of the questionnaire sheet to the subjects and handed back to the researcher upon completion. Field work of the present study was carried out in three months from end of February to the end of May, 2016

\section{Administrative Design}

An official permission was attained from Mansoura University Hospital administrator for conducting the study.

\section{Ethical considerations:}

Prior to the initial interview, explanation of the nature and the aim of the study were done by the researcher to entirely nurse mangers included in the study. Furthermore, a verbal consent was attained from each participating prior to inclusion into the study. The researcher highlighted that the contribution is unconditionally confidential and voluntary as of the subjects' anonymity is assured absolutely through the entire study.

Statistical Design: The collected data were ordered, tabularized and analyzed statistically via SPSS software (Statistical Package for the Social Sciences, version 21, SPSS Inc. Chicago, IL, USA). For quantitative data, the range, mean and standard deviation were calculated. For qualitative data, comparisons between two groups and more were done using Chisquare test $\left(\chi^{2}\right)$. For comparisons between means of two groups of parametric data of 
independent samples, student t-test was used. For comparisons between more than two means of parametric data, $F$ value of ANOVA test was calculated. Relationship between variables was evaluated using Pearson's correlation coefficient (r). Significance was assumed at $\mathrm{p}<0.05$ for interpretation of results of tests of significance.

The collected data were ordered, tabularized and analyzed statistically via SPSS software (Statistical Package for the Social Sciences, version 21, SPSS Inc. Chicago, IL, USA). For quantitative data, the range, mean and standard deviation were calculated. For qualitative data, comparisons between two groups and more were done using Chi-square test $\left(\chi^{2}\right)$. For comparisons between means of two groups of parametric data of independent samples, student t-test was used. For comparisons between more than two means of parametric data, $F$ value of ANOVA test was calculated. Relationship between variables was evaluated using Pearson's correlation coefficient (r). Significance was assumed at $\mathrm{p}<0.05$ for interpretation of results of tests of significance.

\section{Results:}

Figure (1): Mean scores and ranking of perceived competency sub items by the studied nursing managers at Main Mansoura University Hospital $(\mathbf{n}=\mathbf{8 8})$.

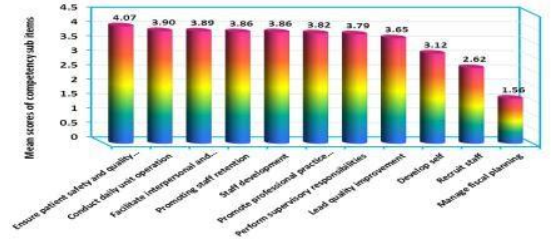

Figure (1) demonstrated mean scores of perceived competency sub items by the studied nursing managers at Main Mansoura University Hospital. The figure showed that competency sub items were compared and significantly different to mean scores. As ensure patient safety and quality care was found the highest and ranked first. Whereas manage fiscal planning as sub item of nursing manger was significantly the lowest and ranked last one.

Figure (2): Levels of perceived total competency by the studied nursing managers at Main Mansoura University Hospital $(\mathrm{n}=88)$.

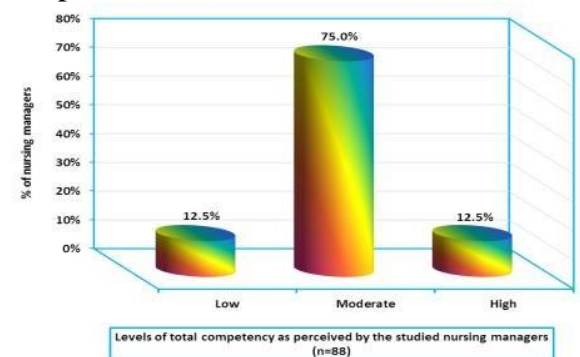

Figure (2) revealed that $12.5 \%$ of nursing managers were in low level and $75.0 \%$ of the studied sample in moderate level, while $12.5 \%$ of them were in high level.

Figure (3): Mean scores of problem solving styles of the studied nursing managers at Main Mansoura University Hospital $(\mathrm{n}=88)$.

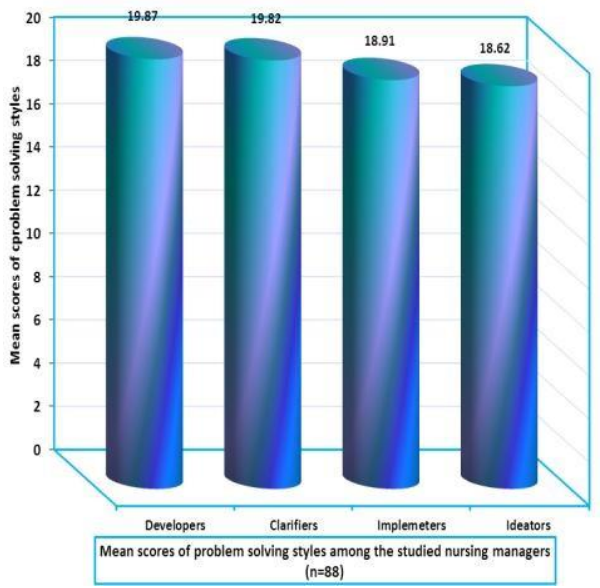

Figure (3) illustrated mean scores of problem solving styles of the studied nursing managers at Main Mansoura University Hospital. According to the figure developer problem solving style had significant high mean scores and ranked 
first. Whereas ideator style had the lowest mean score and ranked the last one.

Table (1): Mean scores and levels of total problem solving styles scores of the studied nursing managers at Main Mansoura University Hospital ( $\mathrm{n}=88)$.

\begin{tabular}{|l|c|c|}
\hline \multicolumn{1}{|c|}{$\begin{array}{c}\text { Total nursing } \\
\text { managers' problem } \\
\text { solving styles }\end{array}$} & \multicolumn{2}{|c|}{$\begin{array}{c}\text { The studied } \\
\text { nursing } \\
\text { managers } \\
(\mathbf{n = 8 8})\end{array}$} \\
\cline { 2 - 3 } & $\mathbf{n}$ & $\%$ \\
\hline $\begin{array}{l}\text { Levels of total } \\
\text { problem solving } \\
\text { styles scores: }\end{array}$ & & \\
$\quad$ Low & 26 & 29.5 \\
$\quad$ Moderate & 56 & 63.6 \\
$\quad$ High & 6 & 6.8 \\
\hline $\begin{array}{l}\text { Mean scores of total } \\
\text { problem solving } \\
\text { styles: }\end{array}$ & & \\
Range (36-108) & \multicolumn{2}{|c|}{$\mathbf{5 7 - 9 6}$} \\
Mean \pm SD & $\mathbf{7 7 . 2 3 \pm 9 . 4 4}$ \\
\hline
\end{tabular}

Table (1) illustrated Mean scores and levels of total problem solving styles scores of the studied nursing managers at Main Mansoura University Hospital. This table indicated more than half of the studied sample of nursing mangers $(63.3 \%)$ had moderate level.

Figure (4): Correlation between Levels of perceived total competency by the studied nursing managers at Main Mansoura University Hospital and their levels of total problem solving styles scores $(n=88)$.

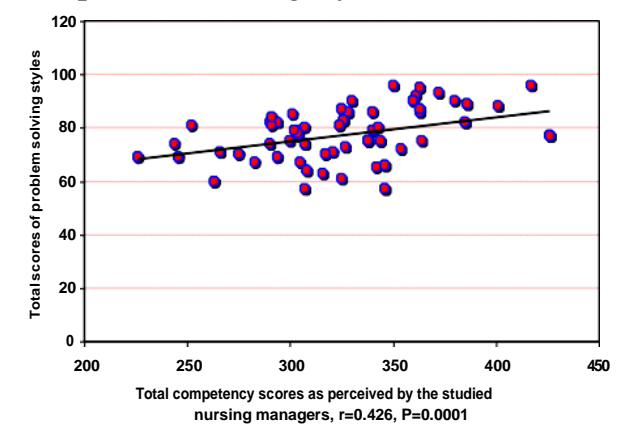

Figure (4) indicated a significant correlation between levels of perceived total competency by the studied nursing managers at Main Mansoura University
Hospital and their levels of total problem solving styles scores.

\section{Discussion}

Nursing manager's competency is vital to promoting healthy work environments, staff performance, staff retention and positive patient outcomes as patient satisfaction and patient safety. Nursing manger competency represented in mastering communication skills, conflict resolution skills and developing self, affects problem solving ability of nursing manager and approaches they adopt solving problems and thereby has a lot to do with their ultimate success in solving the problems ${ }^{21}$.

The present study revealed that competency sub items related to ensure patient safety and quality of care is ranked (rated) highest followed by the sub item conduct daily unit operation. This may be due to the pressingly need for delivering high quality, efficient care and ensuring patient safety. As MUH, serves the whole delta region and this means increased numbers of patient's admissions. These increase its quest for high quality and better patient safety. So, it seeks to increase awareness between nursing mangers, especially head nurses that represent a great portion, about importance of being competent and congruent with updating issues of patient safety and quality of care. This is achieved through 24-hours responsibility for operation of a patient care unit and ensuring efficient application of nursing care.

These results agreed with Fennimore\& wolf (2011) who indicated that management competency in ensuring safety and quality care is as vital to patient care as the care that is provided ${ }^{\mathbf{2 2}}$. These results congruent by Covey (2004) who revealed that high quality health service do not happen without competent and skillful nursing manger ${ }^{23}$. In the same line Chase (2010) reported that efficiently perform 
quality care and improvement process have the highest rating ${ }^{24}$.

The finding of this study in contrast with Deona (2006) who reported that performing supervisory responsibilities is rated highest competency domain by nursing mangers ${ }^{19}$. As well, Haurani et al. (2007) found that communication and professionalism were rated to higher scores on the other competencies ${ }^{\mathbf{2 5}}$. Additionally, Higa and Terviza (2005), who revealed that leadership is considered the most imperative competence and the efforts of nursing mangers to cultivate such competence, strengthens the opinion that the job market is essentially demanding nurses have knowledge of leadership and apply such knowledge ${ }^{\mathbf{2 6}}$. As well as, Mathena (2002) conceptualize that staff development as a skill set needed by nurse managers to effectively support and lead nursing staff ${ }^{27}$. And with Rao (2007) who found that job knowledge is the most vital competency requested to be successful on the job. He also indicated that effective communication skills, hard work, calmness, team skills are frequently used competencies of managers ${ }^{28}$.

The finding of the present study indicated that competency sub item, mange fiscal planning is rated lowest by the studied nursing mangers followed by recruit staff. This was unfortunately because of nurse manager in MUH has neither received training in the nursing program to successfully manage the budget nor been provided the opportunity to manage a budget under the guidance of a mentor. The hospital has not developed a succession or training program that would allow nursing managers to practice budget management skills. The policies applied in the hospital do not give the nursing mangers the access to deal with budgeting and other fiscal issues as managing the pay roll, and monitoring the budget.
These results agreed with Baxter (2013) who found that financial management is the lowest rated perceived competency of the studied sample of nursing mangers ${ }^{29}$. As well, Karathanasi, et al., (2014) reported that financial management competencies were identified as the least necessary as perceived by nursing mangers ${ }^{30}$. And theses finding was in the same line with Kondrat's (2001) who indicated low rating of financial management category 31. In contrast, MacLeod (2012) revealed that financial management is noted to be one of the crucial categories of competence for success of nurse manager ${ }^{32}$. As well, Clark (2015) indicated that financial management and budgetary skills is a prerequisite necessity for competent nurse manger. As nurse manger have effect on the bottom line of health care organizations via controlling expenses of patient care on daily base ${ }^{33}$.

The finding of the present study indicated that nursing managers had moderate level of competency. This may be due to the frequency of performing competency sub item, mange fiscal planning is low because majority of nursing mangers don't participate in developing or monitoring the budget, or have the access to manage the pay roll. As well, the frequency of performing activities related to recruiting staff was low expect for encouraging potential job candidate's to have shadow experience and learn from experienced nurses. The hospital also promotes internship programs. Additionally small numbers of nursing mangers showed high frequency of performing activities related to developing self as having membership of professional organization, delivering presentations to professional groups and play a leadership role in these organizations. This was agreed with yang et al., (2014) who reported that competency of nurse mangers were in moderate range ${ }^{34}$. As well, khodgaria, et 
Heba Rabie Hagras et. al.

al., (2011) who reported that majority of the study sample was moderate competency level and they were proficient grounded on banner's skill acquisition model and after training interventions it was improved to high level ${ }^{\mathbf{3 5}}$.

These result in contrast with pillay (2009) who reported that there is a deficiency of management competency and capacity inside the South Africa public health sector. The fact that nurse managers in this sector appraised themselves as at least 'reasonably competent but not good' in all but one of the competencies submits that they lack confidence in their capacity either since they don't have the required management skills or as they lack selfcredence. Anyway, this has the prospective to hinder service provision and the revolution of public sector into a more effective and efficient service ${ }^{36}$. As well, Meretoja (2004) self-assessed overall scores indicated a high level of competence across categories. The Nurse Competence Scale data were normally distributed. The higher the frequency of using competencies, the higher was the self-assessed level of competence ${ }^{37}$. In this respect, Stobinsiki (2011) indicated that significantly higher mean scores on the overall competency level in the studied group $^{38}$.

Analysis of data of this study revealed that developer creative problem solving style achieving the highest mean scores and ranked first followed by clarifiers, implementers and then ideators. This is due to nursing mangers not only stops on generating ideas that are useful to solve illdefined problem that arise from their complex working environment, but also are concerned with practical applications and the reality of the task. They strive for more revising and break the board problem into steps to examine it clearly from all angles. Also, they need to explore the strengths and weakness of the potential solutions and take time to develop a workable solution for such complex problem. And this is agreed with Treffiner, et al., (2008) who reported that higher scores are achieved by developer problem solving styles than other styles ${ }^{\mathbf{1 5}}$. As well, Fitzjarrell (2011) who indicated the highest percentage of participants reported a preference for the developer problem-solving style ${ }^{39}$. And in contrast with Puccio, et al., (2004) who found that the implementer creative problem solving style having the highest mean scores followed by ideators, clarifier and the least mean scores is for developers ${ }^{40}$.In this respect, Mann (2003) reported that clarifiers creative problem solving style was the most common among managers and was the dominant style preference for nine of eleven of the subject area groups identified ${ }^{\mathbf{4 1}}$. In the same line, Ding (2013) reported that a relatively larger percentage of the studied sample with high preference of clarifier, followed by ideator, implementer and developer ${ }^{\mathbf{4 2}}$.

Additionally, Wellman (2014) indicated that the dominant creative problem solving style was implementers of the study sample ${ }^{43}$.

The finding of the study revealed that levels of the total problem solving scores as perceived by the studied sample nursing mangers are moderate. This may be due to the creative problem solving styles is a new concept to deal with in such working environment that carried many factors that hinder creativity in problem solving. Insufficient access to information decreases manger knowledge that in turn affecting their creative problem solving capacity. They receive little direction, and guidance that allowing for more Successful creative problem solving. Hence, all of this affecting their perception to their problem solving style in creative problem solving process. And these results consistent with Terzioglu (2006) who reported that the total average score of the nurse managers' problem-solving was 
NURSING MANAGERS' COMPETENCY AND THEIR etc...

moderate. The manner nurse managers participating in this study perceived themselves in problem-solving that they have problem-solving skills at a desired level ${ }^{44}$.

The finding of the study also revealed that perceived level of competency of the studied sample nurse manger was significantly related to levels of total problem solving styles. This is due to increased level of competency means increased knowledge and management skills as leadership, teambuilding, motivation and conflict management for effective performing the job. In such complex working environment in MUH, that characterized with poor resources of materials and manpower's and acuity of care. These engaging managers in creative activities to deal with complex and illdefined problems that arise and making them seeking to more information that in turn enhance their problem solving styles. And this is agreed with Buonncontro and Ghosh (2014) who reported that the greater employee's competency and creative self-efficacy. The further they expected creative behaviors of him or her and of the creative work environment ${ }^{45}$. As well, Mumford, et al, (2002) discussed creative work as being contextualized and indicated that the success of creativity rest on the competencies, capabilities, forces, capitals, and socio technical system in which employees find themselves ${ }^{\mathbf{4 6}}$.

\section{Conclusion}

Nursing managers at MUH had moderate competency level. On the other hand, the level of total problem solving styles as perceived by nursing mangers was moderate. Furthermore, a developer problem solving style was the dominant. There was significant relation between nursing manger competency level and problem solving style.

\section{Recommendation}

- Establish systems, protocols, policies and strategy to enhance nursing manger competency level

related to managing financial

planning and recruitment activities.

- Provide training programs to nursing mangers to enhance their competency level.

- $\quad$ Provide training programs about the importance of creativity for enhancing organization ability and efficiency, and how mangers can use their problem solving styles effectively.

- Use the finding of the study as a blue print to improve working environment that foster competency and creative ability of the nursing mangers.

- Seek continuous learning opportunities for nursing mangers and membership in professional nurse organizations that facilitating their professional development.

- Incorporate a competency-based assessment format in future selection of nursing managers' at all three levels. A broader and more structured approach may be needed.

- Develop and communicate a managerial competency model formally to employers and staff representatives, personnel managers, and others involved in nursing manager selection.

References

1.Purcell, L., \& Milner, B., (2005): Management Development In Healthcare : Exploring The Experiences Of Clinical Of Clinical Nurse Mangers .Journal Of European Industrial Training 29(9):751-763

2. Marquis, B., \& Huston, C., (2009): Leadership Roles \&Management Functions in Nursing, Theory and Application, 6th Edition. Chapter 3: Twenty-First Century Thinking About 
Leadership and Management Wotters Kluwer, Lippincott Williams \&Wilkins, New Delhi Pp.51-71

3. Meretoja, R., \& Leino-Kilpi H., (2003): Comparison of Competence

Assessment Made By Nurse Managers and Practicing Nurses.

Journal of Nursing Management 11 (6):404-409

4. Garman, A. N., \& Johnson, M. P. (2006): Leadership Competencies: An Introduction. Journal of Healthcare Management, 9(51):13-17.

5. Robertson, T., \& Callinan, M., \&Bartram, D., (2002): organizational effectiveness: the role of psychology. 1st edition, john willey \&sons, LTD, p. 251

6. O'rouke, M., (2007): Role Based Nurse Manger: A Linchpin To Practice Excellence. Nurse Leader, 5(4): 44-48.

7. Finkleman, A., (2012): Leadership and Management for Nurses Core Competencies for Quality Care, 2nd Edition. Pearson Education Inc. Chapter (1): Conceptual Base for Leadership and Management P. (20).

8. Hamidizadeh, M., (2003): Study Of Behavior and Structure of KnowledgeBased Human Source Problem-Solving Methods. Magazine of Development and Management Process 60 (1):12-25.

9. Dewett, T., (2004): Employee Creativity and the Role of Risk. European J. Innovation Management, (4): Pp. 257-266.

10. Ghorbani, M., \& Heravi, S., (2011): the relationship between mangers problem solving method and employees' trend toward participation in organizational decision making. World applied science journal 12(10):1866-1876

11. Fontaine, R., (2008): problem solving: an Islamic management approach, cross cultural management an international journal, 15(3):264-274
12. Proctor,T., (2005) :Creative Problem Solving For Mangers Developing Skills For Decision Making And Innovation. Chapter One: Creativity and Its Importance in Business, 2nd Edition. Routledge Taylor and Franc Publication P. 6-7.

13. Prophey, D., (2001): Comparing the Attributes, Activities, and Performance of Divergent and Convergent and Combination Thinkers. Creativity Research Journal .13(3):4-39

14. Erozlean, A., (2014): Analysis of Social Problem Solving and Social Self-Efficacy in Prop stile Teachers. Educational Science: Theory and Practice .14(2):447-655.

15. Treffinger, J.D., \&Selby, E., \&Isaksen,S., (2008) : Understanding Individual Problem Solving Style :Akey To Learning And Applying Creative Problem Solving Styles Vol. 18 :390-401 Available On Line At Www.Csiencedirect.Com

16. Tonyperino, G., (2005): Toward More Innovative Program Management. Defense Acquisition Review Journal Pp54-55 Retrieved At 26-1-2016 Available At Www.Au.Af.Mil/Au/Awc/Awcgate/.../ Perino_Arj05febmar.P

17. Daire, I., \&Cilson,L., \&Dary,S., (2014): Developing Leadership And Management Competencies In Low And Middle Income Country Health Systems :A Review Of Literature. RESYST (Resilient Response Health System) Working Paper (4) P.4, 6 Retrieved At 15-1-2016. Available At

Http://Webcache.Googleusercontent.Com/ Search?Q=Cache:Reidcgzqdgej:Resyst .Lshtm.Ac.Uk/Sites/Resyst.Lshtm.Ac. Uk/Files/Docs/Reseources/Wp4_Devel oping\%2520leadership \%2520and $\% 252$ 0management $\% 2520$ competencies.Pdf $+\& \mathrm{Cd}=10 \& \mathrm{Hl}=\mathrm{Ar} \& \mathrm{Ct}=\mathrm{Clnk} \& \mathrm{Gl}=\mathrm{Eg}$

18. Jafri, M., (2010): Organizational Commitment and Employee's 
Innovative Behaviors: A Study in Retail Sector. Journal of Management Research, 10(1): 62-68

19. Deonna, J., (2006): Developing And Validating An Instrument To Measure The Perceived Job Competencies Linked To Performance And Staff Retention Of First Line Nurse Manager Employed In A Hospital Setting. Published Doctor of Philosophy Thesis. The Pennsylvania State University.Pp:68, 133-7.

20. Puccio, G. J. (2002): You're Thinking Profile - A Tool for Innovation. Evanston, IL: Thinc Communications Available atwww.foursightonline.com

21. Baston, V. D., \& Yoder, L. H, (2012): Managerial Coaching: A Concept Analysis. Journal of Advanced Nursing, 68(7):P.1659.

22. Fennimore, L., \& Wolf, G. (2011): Nurse Manager Leadership Development: Leveraging the Evidence and the System-Level Support. The Journal of Nursing Administration, 41(5): 204-210. Doi: 10.1097/Nna.0b013e3182171aff

23. Covey, S. R., (2004): The 7 Habits Of Highly Effective People: Restoring the Character Ethic [Rev. Ed.]. New York: Free Press.

Available at Www.Worldcat.Org/.../7Habits-Of-Highly-Effective-Peop retrieved at31-8-2016

24. Chase, L k., (2010): Nurse Manger Competencies. Published Doctor of Philosophy Thesis, University of Lowa: 1-76

25. Haurani, M.J., \&Rubinfeld, I., \& Rao, S., \& Beaubien, J., \&Musial, J.L., Parker, A., \& Reickert, C., \&Raafat, A. \& Shepard, A., (2007): Are the Communication and Professionalism Competencies the New Critical Values in a Resident's Global Evaluation Process? Journal of Surgical Education, Vol. 64: 351-356
26. Higa, E., \&Trevizan, M., (2005): The Style of Leadership Idealized By Nurses. Rev. Latino-Am. Enfermagem. 13(1): 59-64

27. Mathena, K., (2002): Nursing Manager Leadership Skills. Journal OF Nursing Administration, 32(3):136-142

28. Rao, T.V., (2007): Global Leadership and Managerial Competencies of Indian Managers A 360 Degree Assessment Of The Competency Base of Indian Managers. Working .Paper Research and Publications, Iima, India .No.2007-06-05 Available at Www.Iimahd.Ernet.In/.../Data/200706-05tvrao.Pdf

Retrieved at 3-8-2016

29. Baxter, C., (2013): The Effect of Coaching on Nurse Manager Leadership of Unit Based Performance Improvement:-Expletory Case Studies .DNP Practice Inquiry Projects .University Of Kentucky College of nursing .P:6.

30. Karathanasi, K., \&Prezerokos,P., \& Marria,M., \& Siskou,O., Kaitelidou,D., (2014): Operating Room Nurse Manger Competencies In Creek Hospitals ,Clinical Nursing Studies .12(2) :16-29

31. Kondrat, B., (2001): Operating Room Nurse Managers-Competence and Beyond, Aorn J. 73(6): 1116-1130

32. Macleod, L. (2012): A Broader View Of Nursing Leadership: Rethinking Manager-Leader Functions. Nurse Leader, 10(3): 57-61.

33. Clark, P., (2015): What Budgetary Skills Do Nurse Mangers Need to Success in A large Healthcare Setting Published Master Thesis .The College Of St, Scholastics, Dulluth, and M N Pro quest Publication: 1-61

34. Yang, L., \&Cui, D., \& Zhoe,Q., \&Shen, S.,(2014): Perspectives From Nurse Mangers On Informatics Competencies. The Scientific World 
Journal Volume (2014) Article Id: 391714:1-5(5pages).

35. Khodgaria,M., \&Vanaki,Z., \& Navipour ,H., \&Vaezi,A., (2011):The Effect Of Nursing Management Development Program On Clinical Competency In Coronary Care Unit :Behood Journal 15(1) :40-50

36. Pillay, R., (2009): Perceived Competences Of Nurse Mangers : A Comparative Analysis Of The Public And Private Sector In South Africa .African Journal Of Business Management 3(9) :496-503

37. Meretoja, R., \& Isoaho, H., \&LenioKilp, H., (2004): Nurse Competence Scale, Development and Psychometric Testing .T A N, Informing Practice and Policy World Wide through Research and Scholarship .47(2): 124-133

38. Stobinski, T., (2011): Competency and Work Environments among Military and Civilian Perioperative Registered Nurses: Predictive Model .Published Doctor of Philosophy Thesis in Health Care Science. Cypress, California Pp.1-208

39. Fitzjarrell,S., (2011): A descriptive Study Of The Problem Solving Styles Of Traditional Patrol And Niecll Borheel Police Officers .Published Doctor Of Philosophy Thesis. Capella University: 1-185

40. Puccio, G., \&Wheeler,R., \&Cassmno,V., (2004) :Reactions To Creative Problem Solving Training

:Does Cognitive Style Make Difference. Journal of Creative Behaviors .38(3) Pp.191-216
41. Mann, M.C., (2003): Identifying the Creative Problem Solving Preferences of Secondary School Educators and Administrator .Published Master Thesis, State University of New York College At Buffalo New York Pp. 100

42. Ding,Y.l., (2013):Exploring The Cross Culture Validity Of Four Sight With Taiwanese Population : State University Of New York Buffalo State :The International Center For Studies For Creativity. P. 30-32

43. Well man, T., (2014): Relationship between Creative Problem Solving Profiles and Career Choice, Published Master Thesis, Honey Collge University Honors P.1-30

44. Terzioglu, F., (2006): The Perceived Problem Solving Ability Of Nurse Managers Journal Of Nursing Management, 1(7): 341-345.

45. Buonncontro, T., \&Ghosh, R., (2014): using work place experiences for learning about affect and creative problem solving: piloting a four stage model for management. International journal of management education 12(2):127-141 available at science direct www.elsevier.com

46. Mumford, M. D., \& Scott, G. M., \& Gaddis, B., \& Strange, J. M., (2002): Leading creative people: Orchestrating expertise and relationships. The Leadership Quarterly, vol.13: 705-750 